\title{
EL FEMINICIDIO DESDE LA ESCUELA POSITIVA
}

\author{
Gabriela Noemí Becerra Ponce ${ }^{a}$ \\ Franchesca Paola Coacalla Paricahua ${ }^{\text {a }}$ \\ Mayli Zunila Ramos Llanqui a \\ Roberto Carlos Quispe Canales ${ }^{a}$
}

\section{INFORMACIÓN DEL ARTÍCULO}

Art. Recibido: $31 / 12 / 2019$

Art. Aceptado: 04/08/2020

Art. Publicado: 10/08/2020

Asesor / coinvestigador: Michael Espinoza Coila

${ }^{a}$ Estudiantes de la Universidad Nacional del Altiplano Puno, Facultad de Ciencias Jurídicas y Políticas - Escuela profesional de Derecho cursando el VI semestre en el periodo 2019-II. 


\title{
RESUMEN:
}

En el presente artículo estudiaremos el feminicidio desde la escuela positiva. Para ello, comenzaremos con una breve descripción de cada escuela penal como son la clásica, la ecléctica y la positiva, para luego desarrollar con mayor amplitud cada postulado de la escuela positiva enfocándonos en el feminicido, delito que cada día se incrementa en nuestra sociedad peruana. De acuerdo a los postulados de la escuela positiva tenemos por objetivos: Analizar si el estudio del delincuente es suficiente para la prevención que propugna esta escuela, determinar si el libre albedrio influye en la conducta del delincuente y analizar si la pena funciona como prevención del feminicidio.

Palabras Claves: Escuela Positiva, Delincuente, feminicidio, libre alberdrio, prevención, política criminal.

\section{THE FEMINICIDE FROM THE POSITIVE SCHOOL}

\begin{abstract}
:
In this article we will study feminicide from positive school. To do this, we will begin with a brief description of each penal school such as the classical, the eclectic and the positive, and then develop with greater breadth each postulate of the positive school focusing on feminicide, a crime that every day increases in our Peruvian society. According to the postulates of the positive school we have the following objectives: To analyze if the study of the offender is sufficient for the prevention advocated by this school, to determine if the free will influences the behavior of the offender and to analyze whether the penalty works as a prevention of femicide.

Keywords: Positive School, Offender, Femicide, Free Alberdrio, Prevention, Criminal Policy.
\end{abstract}




\section{INTRODUCIÓN}

Aunque vivimos en un mundo "civilizado" donde aparentemente ya no hay diferencias ni prejuicios de ningún tipo entre varón y mujer y donde nuestra leyes que buscan resolver los problemas de la sociedad, cambian, se modifican en virtud de hallar mejores políticas criminales, continuamos viviendo esa marcada discriminación estructural que hace muy frecuente el abuso que se cometen casi a diario en contra del mal llamado "sexo débil". Como respuesta a ello este artículo estudia algunos aspectos de este amplio hecho delictivo a partir de la perspectiva de la escuela jurídico penal positiva para que mediante este delito veamos la eficacia de cada postulado de esta escuela, en relación no solo del feminicidio sino del delito. Abordando el definir si para el punto de mira del derecho penal es solo al delincuente y estudiando teorías mantenidas por el determinismo en las cuales nos preguntaremos si la conducta del feminicida es determinada y si este sujeto posee una elección al momento de cometer este delito. A su vez tener incidencia en este importante postulado de la prevención y analizarlo mediante la política criminal que el Perú adopta ante este hecho. Todo ello en virtud del alto índice de feminicidios que se han desarrollado en los últimos años y que no da muestra de una mejora hacia los sectores mal vulnerados como son el colectivo de mujeres y el estudio de la asertividad de la escuela elegida para el presente artículo.

Si bien es cierto el positivismo es de aplicación casi total en américa latina. Sin embargo es correcto preguntarnos hasta qué punto sus hipótesis encajan en el nuestros días. Por ello es que se elige esta escuela dentro de las tres principales que se estudiaran sucintamente.

\section{Escuelas jurídicas penales}

El hablar de la escuela Positiva y sus postulados, es un tema que conlleva a estudiar brevemente la escuela Clásica, siendo esta una postura anterior al positivismo que rebatía diversos puntos y de manera sucinta la escuela ecléctica.

\section{Escuela clásica}

Esta escuela propugnaba el dogma de la libertad, el cual hace iguales a todos los hombres (sin diferencias entre el hombre delincuente y no delincuente) y fundamenta la responsabilidad: el absurdo comportamiento delictivo solo puede comprenderse como consecuencia del mal uso de la libertad en una situación concreta, no a pulsiones internas ni a influencias externas (Diaz, Montenegro, \& Martínez, 2012).

Existe algo muy importante en la escuela clásica que se recoge de sus autores: la defensa de las garantías individuales y su reacción contra la arbitrariedad y los abusos de poder. Se reconocen como representantes destacados de la escuela clásica del derecho penal, además de Cesare Beccaria, entre otros a Giovanni Carmignani, Pellegrino Rossi y Francisco Carrara (Díaz, Montenegro y Martínez, 2012).

Se comenzó a reflexionar de forma orgánica sobre el delito tal como nos interesa, ya que el hombre por tener naturaleza gregaria no puede ser un anacoreta, sino vivir en grupo; es allí donde se ha necesitado normas que se han ido creando y formalizando par la regulación de las relaciones entre los componentes; por eso que el delito como infracción de normas, siempre ha preocupado al hombre y las respuestas se han perdido. (Díaz, Montenegro y Martínez, 2012) 


\section{Escuela positiva}

A finales del siglo XIX, el Positivismo Criminológico dio paso a una nueva era, basada en el método científico, un pensamiento que vino a sustituir a la Escuela Clásica, sus mayores impulsores Enrico Ferri, Raffaele Garófalo y Cesare Lombroso. Esta nueva etapa aunaba distintas visiones, desde lo antropológico hasta lo sociológico, pasando por la Psicología, Biología y Psiquiatría, todas éstas formadas con un único propósito, crear una base rigurosa de conocimientos basados en el método empírico y la robustez científica y superar la anterior etapa carente de todos estos procedimientos. está estrechamente ligado a la búsqueda metódica sustentada en lo experimental, rechazando nociones religiosas, morales, apriorísticas o conceptos abstractos, universales o absolutos, Lo que no fuese demostrable materialmente, por vía de experimentación reproducible, no podía ser científico (Blanquer, 2014).

Según lo plantea Jimenez de Asua, desde el punto de vista filosófico la Escuela Positiva nace como una reacción contra el excesivo individualismo y, a través de las evoluciones de Ferri, llega a encontrar en la doctrina socialista su fundamento político - social (Blanquer, 2014).

El positivismo está estrechamente ligado a la búsqueda metódica sustentada en lo experimental, rechazando nociones religiosas, morales, apriorísticas o conceptos abstractos, universales o absolutos, Lo que no fuese demostrable materialmente, por la experimentación no podía ser científico. El postulado de esta escuela se basa en el culto a los hechos, a los fenómenos, a lo dado; toman patrones de las ciencias naturales y pretenden trasladarlos al derecho penal. El positivismo criminológico, destronaría al hombre, privándole de su centro y de su reinado, al negar el libérrimo control del mismo sobre sus actos y su protagonismo en el mundo natural, en el universo y en la historia, el positivismo criminológico inserta el comportamiento del individuo en la dinámica de causas y efectos que rige el mundo natural o el mundo social: en una cadena de estímulos y respuestas, determinantes internos (biológicos) o externos (sociales). (Díaz, Montenegro y Martínez, 2012).

\section{Escuela ecléctica}

La inconciliable pugna mantenida entre los clásicos y positivistas determino la aparición a finales del siglo XIX, de una serie de tendencias de signo ecléctico que trataron de superar al extremismo característico de ambas escuelas. A este conjunto de doctrinas se denominó Positivismo Crítico, que el fondo es la constitución de ambas escuelas.

Una posición de la tercera escuela ecléctica con representantes como Manuel Carnevalle y Bernardino Alimena; coinciden con los positivistas en la concepción del delito, al contemplarlo en su aspecto real como fenómeno natural y social, y en su comprensión de la razón de la justicia penal que ve en la defensa de la sociedad. En lo relativo a la pena la conciben como un instrumento de defensa social y de readaptación del delincuente. (Cuarezma y Houed 2000).

\section{Análisis de los postulados de la escuela positiva}


Journal homepage: http://revistas.unap.edu.pe/rd/ E-mail: revistaderecho@unap.edu.pe

\section{Punto de estudio de la justicia penal en el feminicidio}

Esta escuela le da mayor importancia al delincuente, a diferencia de la escuela clásica que indicaba que el punto de mira de la justicia es el delito. Pues mediante este postulado se ve el delito solo como una manifestación del estado peligroso del delincuente.

En este postulado lo primero a analizar será el DELINCUENTE, es aquí donde se plantea ¿Quién es el delincuente? En respuesta a ello uno de sus representantes, Cesare Lombroso; que analizaba cráneos y la morfología el carácter de los delincuentes y enfermos mentales para concluir que existían "tipos de delincuentes" esta respuesta lo llevaron a una tesis de un criminal "nato" determinado por aspectos biológicos y antropológicos; estos serán tratados con mayor fuerza por la Criminologia Antropologica. Enrique Ferri "perfecciona la teoría y y estudia los factores como "causas" de la delincuencia y propone una serie de medidas alternativas a la pena preventiva entendiendo que habían problemas de orden social, económicos o politicas" (Marco del Pont). Finalmente al perfil del delincuente, Garofalo añade que "el delito es consecuencia de anormalidades psicológicas o morales hereditarias del delincuente, haciendo énfasis en que tales anormalidades eran distintas a la enfermedad mental".

\section{Determinismo en el delito indicado}

Al hablar de feminicidio el delincuente desde la perspectiva de Lombroso no tiene cabida, puesto que su análisis antropológico propuesto quedo desfasado. Hoy en día encontramos que algunos no presentan asimetría en el rostro o desarrollo occipital. Sin embargo se tiene una nueva determinante biológica, esta es el sexo. En 1976 Diana Russell emplea la palabra "feminicidio" ante el Tribunal Internacional sobre Crímenes contra las Mujeres, en Bruselas, y lo define como el asesinato de mujeres por hombres por ser mujeres. (Observatorio de politica criminal Jose Hurtado Pozo, 2017) Esto debido a la brecha de género existente. Lo mencionado es acogido por oficinas de Centro de Emergencia Mujer quienes reportan preliminarmente como casos de feminicidios aquellas figuras donde un hombre mata a una mujer.

En cuanto al estudio del sujeto en el feminicidio a partir de las ideas de Enrique Ferri, encontramos el delincuente poseerá factores sociales, factores culturales, y variables.

Como factores sociales tenemos la ya mencionada brecha de género, que conlleva a múltiples puntos especialmente la violencia de género que en su mayoría se da en los lazos sentimentales, parte de ello es también la situación de control sobre la víctima.

Los medios de comunicación es otro factor. En estos días en los que los crímenes son más crueles, la el tacto de algunos medios al relatar morbosamente datos detallados, puede contribuir a este clima de violencia.

En cuanto a los factores culturales la crianza, la valoración de la mujer en la cultura, las creencias y la forma de llevar la relación de pareja son algunos que conllevan al varón en volverse un potencial victimario o asesino de la mujer. Reflejo de esto en nuestra sociedad tenemos la célebre frase "Amor serrano, más te pego más te quiero"; esta frase si bien no siempre se lleva a su interpretación literal, demuestra la idea de supremacía del varón sobre la mujer que se arraigó la sociedad puneña de hace unos años, especialmente en la zona rural donde el varón salía a buscar el sustento y las mujeres se quedaban de amas casa. Estos oficios fueron cambiando y la mujer ahora sale a la calle al trabajo, en nuestra zona el comercio en su mayoría, esta situación creo 
Journal homepage: http://revistas.unap.edu.pe/rd/ E-mail: revistaderecho@unap.edu.pe

a algunas una situación de empoderamiento incluso a veces desproporcionado. Pero para otras que aún no se abren a esta alternativa viven con rezagos de lo que fue la supremacía del varón en el hogar y la relación e incluso no solo con la idea sino con la forma de esto la violencia familiar, que en su mayoría es lo que conlleva a un feminicidio.

Las estadísticas que sustentan esta idea, son las que muestran que en Puno de los casos presentes de femincidio en el año 2018 y 2019-I.

En cuanto a las variables tenemos la edad, la ocupación, la relación con la victima; estos factores entre otros por referirse a rasgos personales derivan y apoyan a dar como resultado los factores psicológicos. Trabajando con la relación que guardaba la victima con su victimario tenemos que la mayoría se da en un vínculo amoroso, incluyendo un marco de violencia tanto física como sexual y algunos casos psicológicos.

FIGURA 1: Reporte estadístico de Centro de Emergencia Mujer y diarios de la Región Puno.

\section{Ubicación del feminicidio}

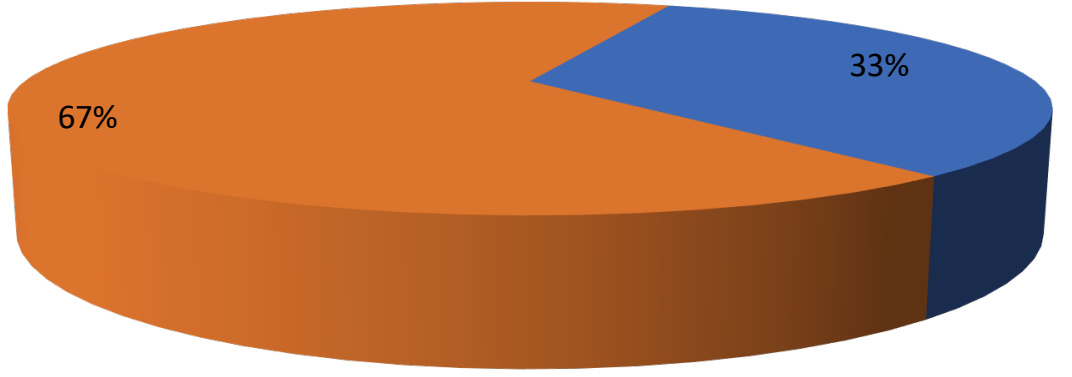

Tabla 1:

Tabla de ubicación del feminicidio.

\begin{tabular}{lcc}
\hline LUGAR & $\mathbf{2 0 1 8}$ & 2019-I \\
\hline PUNO - URBANO & 2 & 1 \\
PUNO - RURAL & 2 & - \\
JULIACA- URBANO & 1 & 1 \\
JULIACA-RURAL & - & - \\
HUANCANE & 1 & 1 \\
CARABAYA & - & 1 \\
MELGAR & - &
\end{tabular}


Journal homepage: http://revistas.unap.edu.pe/rd/ E-mail: revistaderecho@unap.edu.pe

$\begin{array}{lcc}\text { YUNGUYO } & - & 1 \\ \text { OTROS } & 1 & 1 \\ \text { TOTAL } & 7 & 10\end{array}$

Centro de Emergencia Mujer y diarios de la Región Puno.

\section{Libre albedrio en el homicida}

La escuela Positiva nos habla de una ausencia de elección en el delincuente. La postura de Cesare Lombroso de que existe un criminal nato conllevo a que la escuela positivista hable de una predisposición desde su nacimiento, por esta es que el delicuente no elegirá serlo.

Para que el feminicidio responda a esta pregunta postura, deberá responder ¿Cuál es el origen del comportamiento homicida? Mediante esto conoceríamos si es una situación congénita, ya que puede responder a una enfermedad psiquiátrica hereditaria o si no responde a esto. A partir de esto viene a colación la postura de Garofalo que menciona, pues el actuar de la persona puede responder al temperamento y carácter de la persona, lo cual constituirá un rasgo de la personalidad o un trastorno de la personalidad. En caso de los segundos, reafirmará la postura del ausencia de libre albedrio. Pues estos trastornos son, "patrones de comportamiento fijos, poco flexibles y que organizan la vida del sujeto en torno a ellos" (Palomo \& Jimenez Arriero, 2009). Sin embargo, esta postura o será suficiente ya que el sujeto pudo actuar por el impulso del momento según su temperamento.

Con mayor veracidad la psicología clínica dará respuesta en esta pregunta sin embargo a favor de la postura de Garófalo tenemos dos situaciones en análisis. 
Journal homepage: http://revistas.unap.edu.pe/rd/ E-mail: revistaderecho@unap.edu.pe

Comenzando por la relación de la víctima tenemos que:

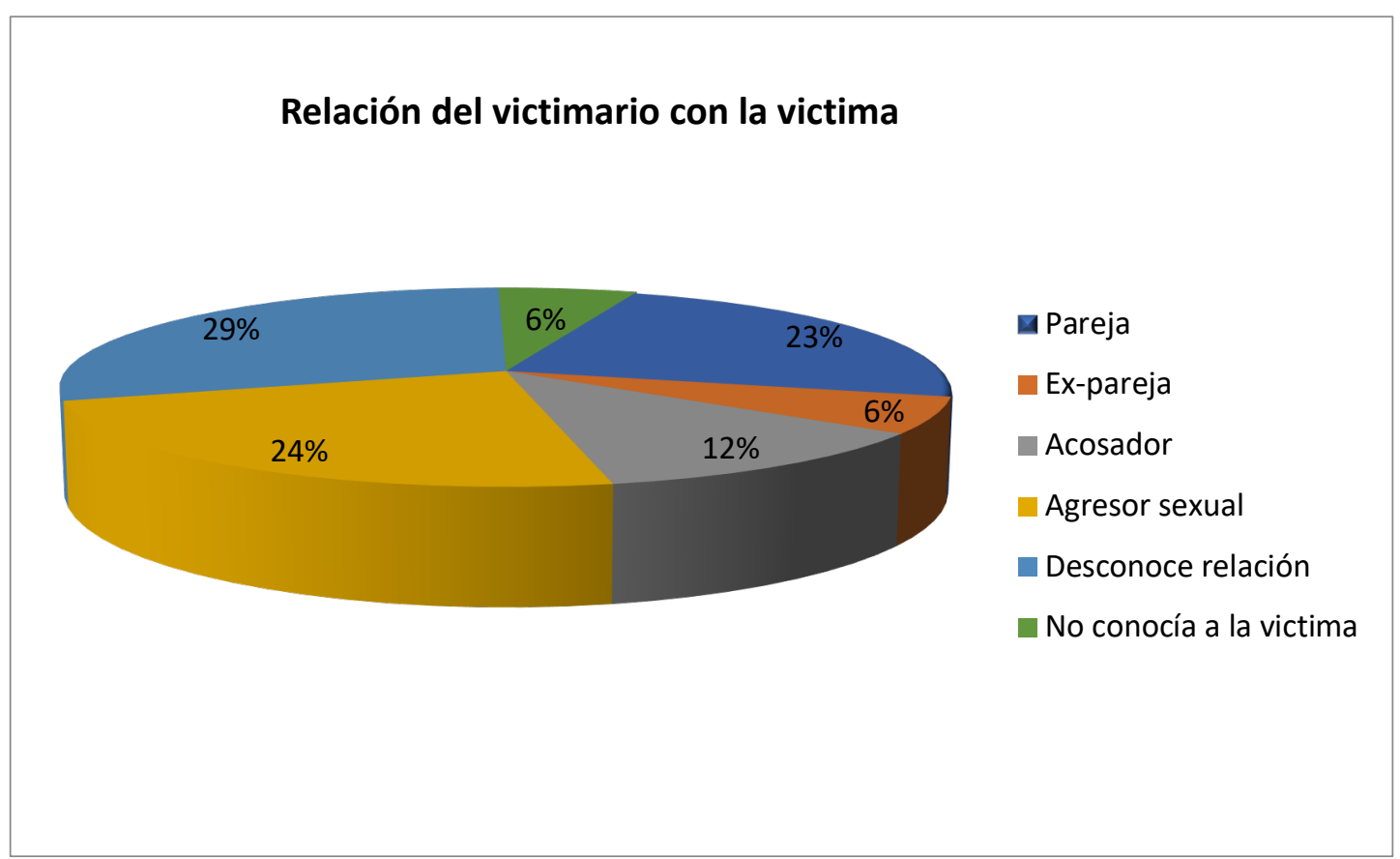

FIGURA 2: Reporte estadístico de Centro de Emergencia Mujer y diarios de la Región Puno.

Donde; El 23\% corresponde a 4 casos en los cuales la relación de pareja es confirmada por medios veraces, el $6 \%$ corresponde a 1 caso donde la familia confirma que el asesino es la expareja de la víctima, el 12\% corresponde a 2 casos donde la víctima no respondió al cortejo del agresor $27 \%$ corresponde a 4 casos en los cuales se registró una violación sexual seguida del asesinato de la víctima, el 29\% corresponde a 5 casos en los cuales no se tiene clara o confirmada por una fuente confiable la relación, los medios y familiares presumen una posible relación sentimental, el $6 \%$ corresponde a 1 caso donde la víctima y el victimario se encontraban enajenados.

Para ello partiendo de la premisa que; el libre albedrio puede presentarse o no. Partiremos del $6 \%$ correspondiente a un caso donde la víctima y el victimario se desconocían; en el presente caso las personas cercanas al victimario mantienen rumores sobre trastornos de personalidad debido a actos sádicos que realizaba con animales. De ser cierto el comportamiento sádico atribuido en conjunto de otros patrones, victimario podría poseer un trastorno de personalidad o incluso incurrir en enfermedades psiquiátricas de mayor estudio como es la psicopatía por el hecho de desmerecer la vida ajena y con esto manejarla a su antojo.

En los otros casos que responden a una situación sentimental, por lo menos se manejaba una relación, lo cual si bien no justifica la agresión, nos puede generar un indicio de que el victimario respondió a un hecho y el mal manejo de su carácter y temperamento, teniendo al segundo como "la tendencia individual a responder de formas predecibles a los hechos del entorno"; lo convirtió en un asesino.

Agregado al último párrafo se tiene el siguiente cuadro donde muestra bajo que medio se realizó el homicidio. 
Journal homepage: http://revistas.unap.edu.pe/rd/ E-mail: revistaderecho@unap.edu.pe

El cuadro que presentaremos tenemos que; 7 de 17 mujeres fallecieron debido a golpes, 6 de 17 debido a estrangulamiento, 3 de 17 por arma blanca, 1 por envenenamiento.

\section{Tabla 2:}

Tabla del medio en que se realizó el homicidio.

\begin{tabular}{lcl}
\hline FECHA & EDAD DE LA VICTIMA & \multicolumn{1}{c}{ MEDIO } \\
\hline $23 / 06 / 2019$ & 16 años & Asfixia mecánica (estrangulamiento) \\
$05 / 01 / 2019$ & 29 años & Golpeada con concreto (fractura craneal) \\
$20 / 01 / 2019$ & 31 años & $\begin{array}{l}\text { Acuchillada (arma blanca punso cortante), golpeada } \\
\text { (equimomas) }\end{array}$ \\
$12 / 02 / 2019$ & 1 año 9 meses & Violación \\
$18 / 02 / 2019$ & 16 años & Asfixia mecánica (ahorcadura, estrangulamiento, sofocación, \\
$17 / 03 / 2019$ & 27 años & sumersión) \\
$01 / 06 / 2019$ & 21 años & Torturada y descuartizada (arma blanca punso cortante) \\
$10 / 06 / 2019$ & 22 años & Violación, golpeada (equimomas) y torturada \\
$14 / 06 / 2019$ & 15 años & Desconoce \\
$16 / 06 / 2019$ & 5 años & Violación, golpeada (equimomas)
\end{tabular}


Journal homepage: http://revistas.unap.edu.pe/rd/ E-mail: revistaderecho@unap.edu.pe

\begin{tabular}{|c|c|c|}
\hline $15 / 05 / 2018$ & 19 años & $\begin{array}{l}\text { Asfixia mecánica (ahorcadura, estrangulamiento, sofocación, } \\
\text { sumersión) }\end{array}$ \\
\hline $26 / 07 / 2018$ & 20 años & Desconoce \\
\hline $08 / 09 / 2018$ & 44 años & $\begin{array}{l}\text { Golpeada (equimomas), Asfixia mecánica (ahorcadura, } \\
\text { estrangulamiento, sofocación, sumersión) }\end{array}$ \\
\hline $06 / 10 / 2018$ & 18 años & $\begin{array}{l}\text { Acuchillada (arma blanca punso cortante) y golpeada } \\
\text { (equimomas) }\end{array}$ \\
\hline $08 / 10 / 2018$ & 21 años & $\begin{array}{l}\text { Golpeada (equimomas), Asfixia mecánica (ahorcadura, } \\
\text { estrangulamiento, sofocación, sumersión) }\end{array}$ \\
\hline $02 / 06 / 2018$ & 49 años & $\begin{array}{l}\text { Golpeada (equimomas), Asfixia mecánica (ahorcadura, } \\
\text { estrangulamiento, sofocación, sumersión) }\end{array}$ \\
\hline $07 / 09 / 2019$ & 25 años & Envenenamiento (intoxicación) \\
\hline
\end{tabular}

Centro de Emergencia Mujer y diarios de la Región Puno.

Esto conlleva a pensar que no todos los asesinatos responden a un hecho premeditado y por ende tal vez solo respondió a la emoción e impulsividad del momento.

Sin embargo, como se menciona al inicio de este apartado para comprobar el diagnostico psicológico de cada asesino y así determinar el perfil psicológico y si este se debe a un trastorno, se debe recurrir a la psiquiatría y otras ramas que aunadas dan respuesta a la Criminología Psicológica, necesitando también de más hechos concretos que aporten en la construcción del perfil de un delincuente. Por ende los dos cuadros responden a una hipótesis al problema sobre el delincuente en el cual la criminología puede ahondar más no solo en una vertiente psicológica.

\section{Importancia de la prevención}

Para hablar de prevención o represión de delitos debemos saber el concepto de "política criminal". Riccardo Cappi define la política criminal como la organización política de los medios para reducir la ocurrencia de delitos u otras situaciones problemáticas vinculadas a la seguridad de una población. La implementación de una política criminal deben tomar en cuenta los actores que se encuentran comprometidos, a título formal y explícito o incluso de manera informal, implícita en ésta. Entre los actores, podemos citar el poder legislativo, el poder judicial y el poder ejecutivo. Este último incluye, de una parte, a actores gubernamentales directa y formalmente inscritos en los sectores de la Justicia 
Journal homepage: http://revistas.unap.edu.pe/rd/ E-mail: revistaderecho@unap.edu.pe

o de la Seguridad y, de otra parte, a los actores que pertenecen a otros sectores del gobierno. (Aponte , Pochak, Charme, \& Rea, 2012).

En el Perú esta política criminal empieza con la erradicación de la violencia contra la mujer, ya que esta trae como consecuencia el delito de feminicidio. Acciones de Gobierno en torno a la violencia contra la mujer (2018) Martín Vizcarra Cornejo Presidente de la República dispuso declarar de interés nacional y prioridad del Estado "La lucha contra la violencia hacia las mujeres" para lo cual:

Constituiremos una Comisión de Emergencia para enfrentar el problema crítico de violencia hacia las mujeres que el país enfrenta.

Declararemos en alerta permanente las comisarías a nivel nacional, para que en las 24 horas del día puedan recibir denuncias y aplicar las medidas de protección correspondientes en salvaguarda de la vida e integridad de las mujeres.

Realizaremos un trabajo articulado y multisectorial para la prevención de la violencia contra las mujeres desde todos los programas y servicios sociales que ofrece el Estado a nivel nacional, liderado por el Ministerio de la Mujer y Poblaciones Vulnerables (MIMP).

En el presente año bajo el liderazgo del Ministerio de la Mujer y Poblaciones Vulnerables (MIMP), el Gobierno del Perú viene desarrollando diversas iniciativas para la toma de conciencia de situaciones de violencia y subsecuentes denuncias, así como para el cambio de estereotipos culturales y condiciones que perpetúan la violencia. Estas acciones incluyen a sectores claves como Justicia, Interior, Educación y Cultura.

Entre las principales acciones del MIMP están las campañas educativas como "La Violencia se pinta de amor" y la app Toxímetro. la ampliación del servicio de la Línea 100, la ampliación de la cobertura de los Centros Emergencia Mujer (CEM) para su atención 24 horas los 7 días de la semana. A ello debe añadirse la estrategia de instalación de 50 CEM en Comisarías actualmente en curso, que impactará en la reducción de los factores de violencia y las iniciativas para el empoderamiento y autonomía económica de las mujeres, entre otras varias medidas.

\section{Tabla 3:}

Comparativo de los casos con características de feminicidio registrados por los CEM según mes de ocurrencia

\begin{tabular}{lccc}
\hline \multicolumn{1}{r}{ Mes / año } & $\mathbf{2 0 1 9}$ & $\mathbf{2 0 1 8}$ & Var. $\%$ \\
\hline Enero & 15 & 10 & $\mathbf{5 0 \%}$ \\
Febrero & 15 & 12 & $\mathbf{2 5 \%}$ \\
Marzo & 13 & 11 & $\mathbf{1 8 \%}$ \\
Abril & 13 & 10 & $\mathbf{3 0 \%}$ \\
Mayo & 11 & 19 & $\mathbf{- 4 2 \%}$ \\
Junio & 19 & 8 & $\mathbf{1 3 8 \%}$ \\
Julio & 15 & 12 & $\mathbf{2 5 \%}$ \\
Agosto & 18 & 11 & $\mathbf{6 4 \%}$ \\
Setiembre & 8 & 10 & $\mathbf{- 2 0 \%}$ \\
Octubre & 13 & 16 & $\mathbf{- 1 9 \%}$ \\
Total & $\mathbf{1 4 0}$ & $\mathbf{1 1 9}$ & $\mathbf{1 8 \%}$ \\
\hline
\end{tabular}


Journal homepage: http://revistas.unap.edu.pe/rd/ E-mail: revistaderecho@unap.edu.pe

En el cuadro se observa el comparativo de los casos con características de feminicidio registrados por los CEM según mes de ocurrencia, donde de manera general hay un incremento relativo en el registro de casos y en los meses de junio y agosto se ve notoriamente el aumento de casos de feminicidio, así como su registro.

Como se registra en el gráfico anterior el índice de feminicidos en el Perú está subiendo notoriamente a pesar de la política criminal que está aplicando el gobierno.

FIGURA 3: Número de casos con características de feminicidio según año -

\section{Número de casos con caracteristicas de feminicidio según año}

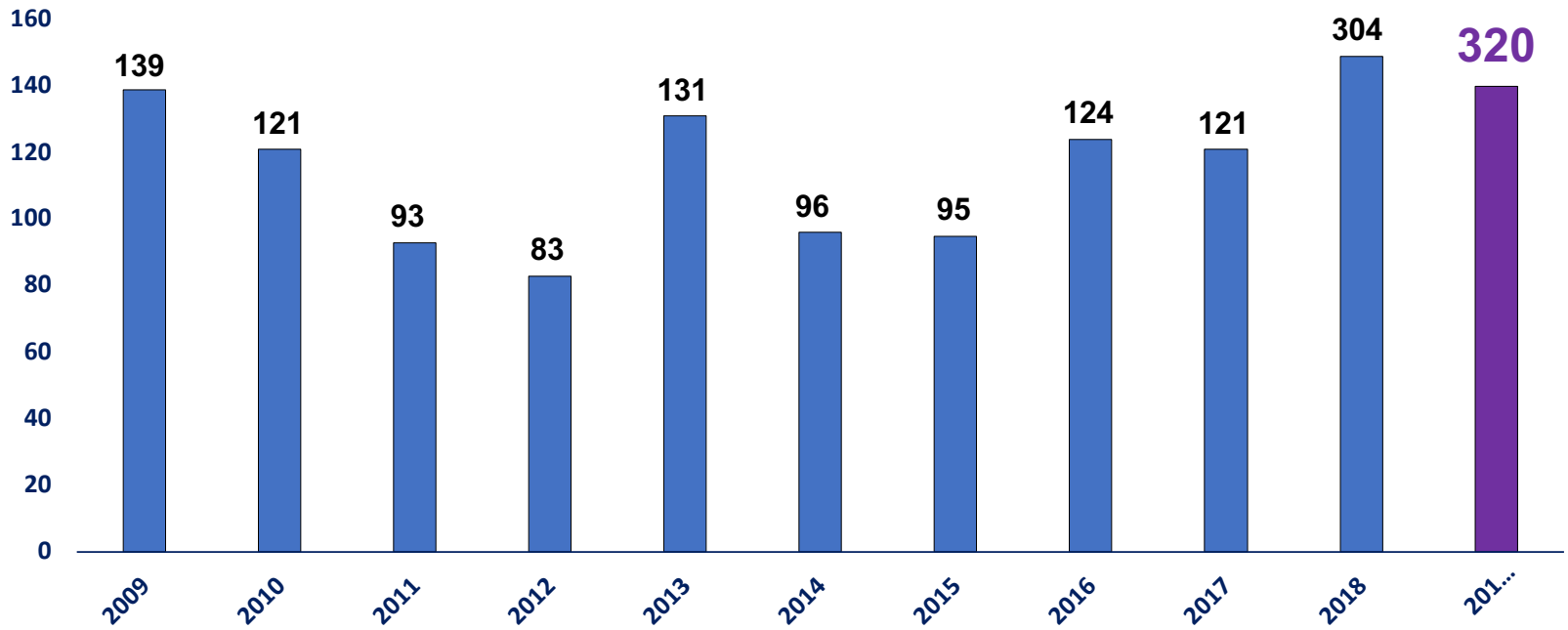

Registrados por los CEM

"El MIMP tiene a cargo todos los casos de feminicidio para darle apoyo articulado, mediante el programa 'Te acompañamos', para trabajar conjuntamente con las otras instituciones del Estado y brindar los servicios a personas que sufren este tipo de situaciones" (Onofre, 2019).

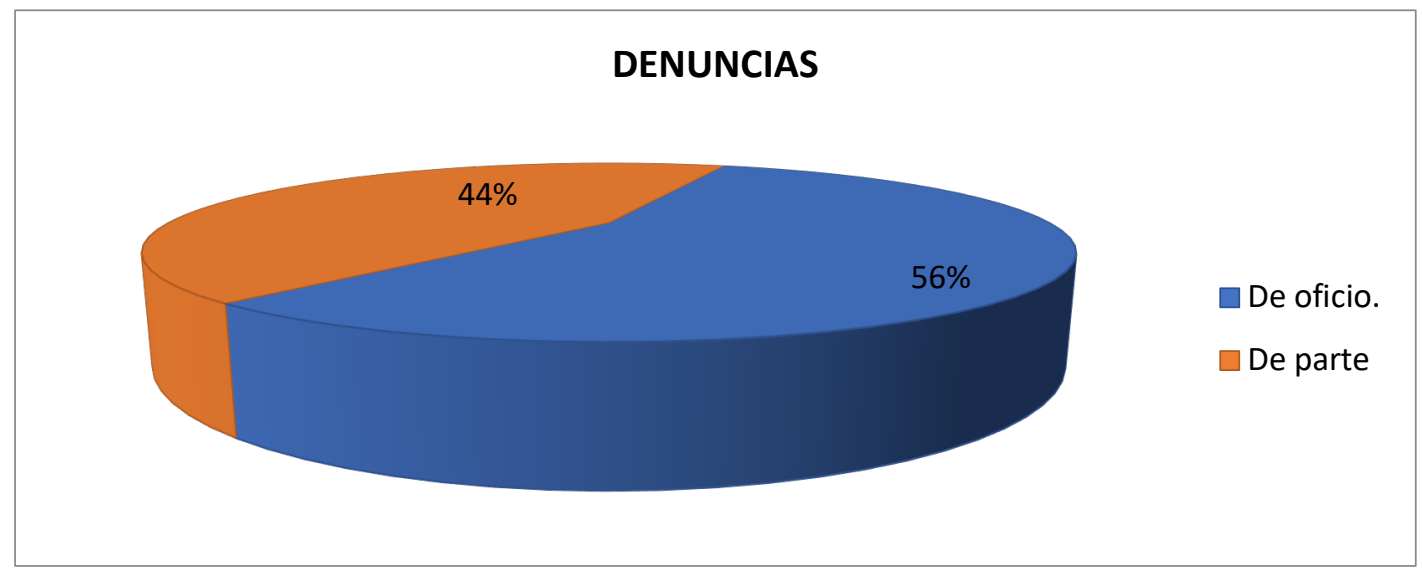

FIGURA 4: Denuncias recibidas en el CEM 
Journal homepage: http://revistas.unap.edu.pe/rd/ E-mail: revistaderecho@unap.edu.pe

Las denuncias recibidas en el CEM, se dan de dos maneras unas de oficio que son recopiladas de medios de comunicación como periódicos, diarios, radio, etc; además de redes sociales (WhatsApp) y de parte cuyas denuncias llegan a través de familiares, vecinos o personas conocida por la víctima.

FIGURA 5: Medidas después de las denuncias - Centro de Emergencia Mujer

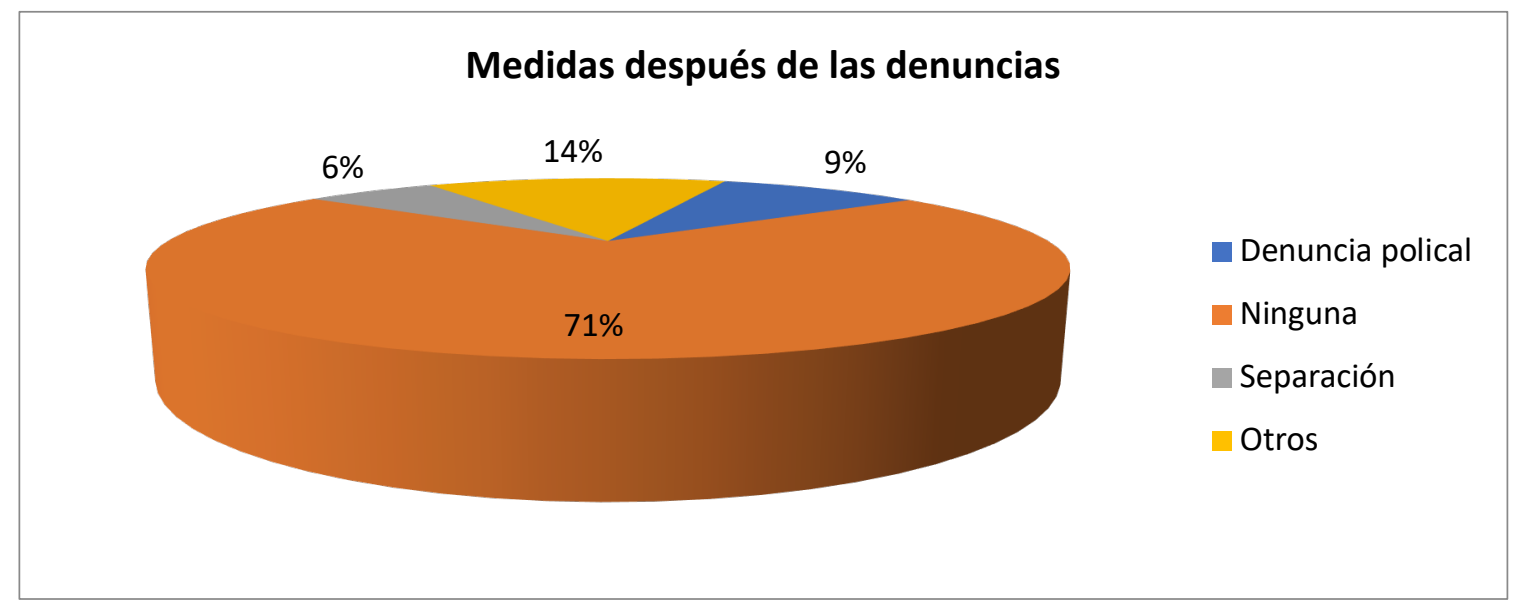

Del cuadro anterior concluimos que en la mayoría de casos el ministerio de la Mujer y Poblaciones Vulnerables en coordinación con el Centro de Emergencia Mujer no se tomó ninguna medida.

Sin perjuicio de ello, enfrentar esta problemática demanda una acción conjunta, concertada y persistente entre los tres niveles de Gobierno, el Congreso, el Poder Judicial, el Ministerio Público, la sociedad civil y los medios de comunicación. Es por ello que resulta importante que los distintos poderes del Estado informen a la ciudadanía sobre las acciones que están realizando para poder combatir y terminar con esta situación lamentable para los peruanos.

Entre otras acciones importantes se establece que la policía podrá ingresar en los hogares donde se desarrollen actos de violencia contra mujeres o integrantes del grupo familiar, a fin de retirar al agresor, que será impedido de regresar al domicilio.

Muchas veces, los policías se veían limitados en su labor porque eran denunciados por violación de domicilio al no contar con una orden judicial para ingresar en la casa. Ahora, al tratarse de situaciones de flagrancia, ya no existirá esa restricción (Acciones para proteger a la mujer, 2018).

Parte de la política criminal en nuestro país es aumentar la pena, según el Diario Comercio en mayo de este año, el Congreso de la República aprobó modificar el Código Penal y aumentar la pena mínima por el delito de feminicidio como una manera de combatir estos casos que vulneran a las mujeres del país. Sin embargo, a pocos días de acabar el año ya se han registrado 143 asesinatos de este tipo, la cifra más alta desde el 2009, según la Defensoría del Pueblo.

Según la información recopilada de las diferentes entidades encargadas de poner en marcha las Acciones de Gobierno, el enfoque en relación al delito del feminicidio es la prevención de la violencia contra la mujer, ya que esta trae como consecuencia la 
Journal homepage: http://revistas.unap.edu.pe/rd/ E-mail: revistaderecho@unap.edu.pe

comisión de dicho delito. Estas acciones concuerdan con los postulados de la escuela Positiva "Prevención más que represión" y la escuela Ecléctica "La finalidad de la pena no se agota en el castigo del culpable. trasciende el mero afán prevencionista o las metas defensitas".

Sin embargo, el aumento de la pena como prevención del delito no está cumpliendo con su finalidad, según Bedoya (2019) a pesar de que las sanciones más duras, hay más casos de feminicidio. El escenario es grave y para los especialistas los casos irán aumentando si no se aborda como problema social. "El marco punitivo no va a resolver el problema, los hechos van a aumentar y los índices de violencia se van a agravar", indicó la penalista y criminóloga María Elena Portocarrero, quien considera que la alta violencia actual se debe entender en torno al problema del machismo, la falta de valores y la decaída salud mental en nuestro país. Advirtió que se está dañando el núcleo familiar.

Perteneciendo esta última medida a la escuela Clásica donde se considera que la pena proporcional al delito. 
Journal homepage: http://revistas.unap.edu.pe/rd/ E-mail: revistaderecho@unap.edu.pe

\section{CONCLUSIONES}

Primero. El estudio solo del delincuente, como la escuela positiva sostiene, es insuficiente para sentar las bases de la justicia penal. Si bien la escuela ecléctica ya concluyó que se debe estudiar tanto el delincuente por incurrir en la falta o delito y el delito, por atentar contra la sociedad. También se debería hablar de la víctima para poder manejar adecuadamente la prevención propugnada por esta escuela.

La teoría del delincuente nato como propugna Lombroso en esta escuela, es decir un estudio antropológico del victimario no tiene cabida en este delito ni en la sociedad, puesto que en nuestros días el delincuente escapa de un perfil morfológico. Sin embargo, los rezagos de ello como propugnan autores moderno son prejuicios sociales para enmarcar el delincuente. Para el feminicidio este perfil biológico erróneamente o no, viene a ser cubierto por el varón quien se muestra como una amenaza para la mujer frente a la sociedad. En cuanto a los factores sociales y culturales, si bien forma de la teoría determinista, estos pueden influir a que algunos sujetos a raíz de su personalidad y características genéticas den paso a un criminal. Esto no se debe confundir con creer que estos factores crean al delincuente

Segundo: El libre albedrio no se cierra en una negativa, pues al descartar la anterior teoría también se descarta esta. Puesto que si bien poseemos homicidas determinados por características genéticas y psicopatológicas; también tenemos homicidas que se debieron al mal control del temperamento y la respuesta ante factores externos. Como ya propugna la escuela ecléctica; existen criminales imputables e inimputables.

En cuanto a los delincuentes inimputables, la pena no poseerá un afán sancionador. Sin embargo no por este hecho debe darse débilmente, se debe procurar un trabajo arduo en cuanto a la recuperación total del delincuente, con un afán de prevención social.

Tercero: La prevención en esta escuela es el punto fuerte. Puesto que en una concepción idealista desde el delito tocado, nosotros no deberíamos trabajar en punir feminicidios, sino en disminuirlos y no solo a través de la pena, también bajo los programas instaurados correctamente ejecutados.

La política criminal si bien es acertada es deficiente. Pues esta trabaja en la protección de la mujer en situaciones de violencia, pero se descuida del potencial agresor; si bien otorga medidas de protección en la relación de ambos. El estado podría trabajar en una prevención más amplia que vaya desde identificar a potenciales sujetos agresores a partir de entrevistas psicológicas en sus respectivos entornos y derivarlos a atención especializada para poder tratarlos adecuadamente antes de que estos se conviertan en homicidas. Esto no solo trabajado a partir de la prevención del feminicidio sino a partir de una prevención contra otros delitos. Gracias a la instauración de políticas públicas de salud mental.

El aumento de la pena como política criminal no tiene efectividad, ya que no se ve ninguna disminución de los niveles de feminicidio, más por el contrario va en aumento. 